\title{
A FLASH OF CULINARY TOURISM: UNDERSTANDING THE INFLUENCES OF ONLINE FOOD PHOTOGRAPHY ON PEOPLE’S TRAVEL PLANNING PROCESS ON FLICKR
}

\author{
BINGJIE LIU,* WILLIAM C. NORMAN,† AND LORI PENNINGTON-GRAY* \\ *Department of Tourism, Recreation and Sport Management, University of Florida, Gainesville, FL, USA \\ † Department of Parks, Recreation and Tourism Management, Clemson University, Clemson, SC, USA
}

\begin{abstract}
This article presents the results of an exploratory study in the online image-sharing community Flickr. The purpose of this study was to profile the users who are fond of online food photography as well as to explore the role of online food photography in their traveling planning process. Grounded in "uses and gratification theory," a mixed method was adopted for this research. Content analysis was employed to understand members' general motivation to participate in different online food photography activities. A series of chi-square and independent-sample $t$ tests was conducted to determine if significant differences existed between active members and not-as-active members. Results of the quantitative and qualitative analyses supported each other. The findings indicated that factors of entertainment, personal identity, and social interaction were the main drivers of participation in online food photography activities. It was further revealed that participants' tourism experiences were recorded as personal photography but shared socially through the use of social media. For active members, food images influenced them in terms of novelty and providing information. Active members also appeared to be more likely to seek out new places to travel for new food experiences, and food photography had a greater influence on where they consider traveling. On the basis of the results, implications for culinary tourism promotion and destination marketing were discussed.
\end{abstract}

Key words: Social media; Food photography; Culinary tourism, use and gratification; Flickr

Introduction

Culinary tourism, defined as "the pursuit and enjoyment of unique and memorable food and drink experiences” (World Food Travel Association, 2012), has emerged as one of the growing areas in the tourism industry (Smith \& Costello, 2009). In 2012, it was estimated that tourists' expenditures on food services in the US reached US\$201 billion, which account for nearly one quarter (23.5\%) of all travel income. This made food service the top category of travel spending in 2012 (US Travel 
Association, 2013). In addition to the significant contribution to the economy, the focus on culinary tourism results from food's central place in one's tourism experiences (Wolf, 2002) and its uniqueness as a tourism product (Ab Karim \& Chi, 2010) as well as its potential as a niche tourism market (Ab Karim \& Chi, 2010).

Indeed, food can no longer be seen as a way to simply satisfy our physical needs. Postmodernists have portrayed food as "embodied material culture" (Dietler, 2007, pp. 222-223) and suggested that our social and cultural identities can be expressed via food (Van der Veen, 2008). Within a destination, food is interpreted as the "core manifestation of a destination's intangible heritage” (Okumus, Okumus, \& McKercher, 2007, p. 253) and has been incorporated into different destination marketing strategies (Ab Karim \& Chi, 2010; Du Rand \& Heath, 2006; Okumus et al., 2007). For tourists, food plays a role within cultural tourism (Scarpato, 2002) and has become one of the main travel motivators in recent years (Boniface, 2003; Long, 2004; Okumus et al., 2007; Quan \& Wang, 2004).

Interestingly, it is observed that the importance of food has continued to increase in various social media sites, such as Twitter, Facebook, and MySpace, where users have posted a vast number of food pictures on a regular basis (Murphy, 2010). In addition, a recent study (Moed, Rosner, \& Van House, 2007) found that food is the most popular theme among all published pictures on Flickr, "a prominent social media photo-sharing community” (Nov, Naaman, \& Ye, 2010, p. 557). It was estimated that more than 6 million food pictures have already been uploaded to Flickr, and this number has increased 10 times from 2008 to 2010 (Murphy, 2010). It is obvious that the rise in food-photo sharing has generated a new trend within popular culture; however, little is known about the influence of online food photography and research exploring the specific relations between food images and social media users' travel planning processes.

In fact, user-generated content carried by social media sites, known as consumer-generated media (CGM), not only reflects individuals' personal interests but also exerts a dramatic impact on other people who access this information. Researchers (Xiang \& Gretzel, 2010) have found that tourists' travel decisions can be reshaped by CGM in terms of electronic word of mouth (eWOM) because many tourists have seen CGM as an authentic and credible source of information (Akehurst, 2009). However, findings on the influence of social media on tourists' decision making have been inconclusive. Due to the diverse nature of social media, additional research has been called for to better understand the way tourism experiences are mediated though the lens of social media (Tussyadiah \& Fesenmaier, 2009) as well as to explore the underlying factors that drive people's active participation and contribution to CGM communities (Lo, McKercher, Lo, Cheung, \& Law, 2011; Wang \& Fesenmaier, 2004).

Despite the increasing popularity of culinary tourism and CGM sites, very few studies have connected these two areas of research. Therefore, the purpose of this research was to conduct an exploratory study on the online image-sharing community Flickr that profiles the food group members, examines the motivation that drives their participation in different online food photography activities, and explores the role of food pictures in their travel planning process.

\section{Literature Review}

\section{Food, Tourism, and Culinary Tourists}

The inseparable relationship between food and tourism has been widely recognized by different scholars (Hall \& Mitchell, 2000, 2002; Mak, Lumbers, Eves, \& Chang, 2012; Quan \& Wang, 2004). Traditionally, food has been perceived as a supporting resource, acting as a supplement to tourism attractions within a destination (Hall \& Mitchell, 2000, 2002). However, this minimal role in the travel experience is arguable. In fact, food experiences are complicated and inextricably linked to one's tourism experience. Quan and Wang (2004) found that food consumption, as an essential part of travel activities, can lead tourists toward peak experiences by producing a sense of enjoyment and satisfaction. Moreover, due to the connection between food and local community, food can be identified as a cultural symbol of an area or destination and determines the way tourists experience local culture as well as defines the destination (Everett, 2008; Frochot, 2003; Kivela \& Crotts, 2006; Okumus et al., 2007; Sims, 2009). 
Tikkanen (2007) has identified five main approaches to examine the role of food in tourism, namely, "food as a tourist attraction" (p. 725), which mainly looked at the food supply as an attraction in well-developed tourist destinations; "foodstuff as a touristic product component” (p. 725), which focused on the food product and consumption structure; "food experiences in tourism" (p. 725), which combined the tourist experience together with gastronomic experiences; "the role of food in culture" (p. 726), which regarded food as an interpretation of local culture; and "linkages between tourism and food production” (p. 726), which generally analyzed the role of culinary tourism rooted from the prospect of the supply chain.

Given the uniqueness and attractiveness of food, culinary tourism has gradually developed into an emerging sector within the tourism industry. According to a national survey conducted by Travel Industry Association, it was reported that current culinary tourists have spent more than one third (36\%) of their travel budget on food-related activities, whereas for those who are currently excluded from culinary activities, more than one half (60\%) expressed a strong interest to pursue culinary experiences in the near future (US Travel Association, 2007). Although culinary tourists appear to be a potential market for tourism practitioners, it is suggested that culinary tourists are not homogeneous; in fact, a spectrum in culinary tourists exists ranging from the centrality of culinary experience (McKercher, Okumus, \& Okumus, 2008) to a periphery of the overall experience. Mack, Blose, and MacLaurin (2009) have divided tourists into two clusters, culinary tourists and nonculinary tourists, and two groups of culinary tourists could be further identified, namely, innovative tourists and noninnovative tourists. Likewise, on the basis of tourist motivation, McKercher et al. (2008) have classified five types of culinary tourists: (1) nonculinary tourists, (2) unlikely culinary tourists, (3) possible culinary tourists, (4) likely culinary tourists, and (5) definite culinary tourists. However, significant differences could not be found between the groups, and it is critiqued that such segmentation of culinary tourists was superficial and the underlying factors that drive tourists' motivation of culinary activities are still unclear (McKercher et al., 2008; Yun, Hennessey, \& MacDonald, 2011).

\section{Tourism Experiences and Online Photography}

According to Larsen (2006), "tourism and photography are modern twins” (p. 226). Urry’s (1990) paradigm of the tourists' gaze, which depicts how tourists perceive a destination and interpret their tourism experience through photography, best exemplifies the intertwined relationship between tourism experiences and tourist photography. This paradigm has guided a number of studies in which tourist photography has been used to examine one's tourism experiences. For example, Markwell (1997) used on-site photographs to analyze naturebased tour experiences. Jenkins (2003) explored tourists' backpack experience through their travel photos, and Garrod (2008) examined tourists' perceive destination images by using the methodology of visitor-employed photography.

Meanwhile, due to the advent of technology, contemporary tourists, who are now equipped with advanced technology and have adapted to using multiple online media, are not content with taking pictures only. It was observed that modern tourists are more likely to take, view, and post pictures online (Lo et al., 2011; Pennington-Gray, Stepchenkova, \& Schroeder, in press; Tussyadiah \& Fesenmaier, 2009; Van House, 2009). Such activities not only allow tourists to record and share their tourism experiences but also have the potential to produce dramatic impacts on a variety of audiences (Tussyadiah \& Fesenmaier, 2009; Yoo, Lee, Gretzel, \& Fesenmaier, 2009). It is found that CGM content not only brings out a sense of pleasure and enjoyment to the viewer (Tussyadiah \& Fesenmaier, 2009) but also serves as an information source for their future travel plans (Yoo et al., 2009).

\section{Use and Gratification Theory and Social Media}

Use and gratification (U\&G) theory is a widely cited theory used in the general media literature and has been used to understand people's motivation for using different types of media (Shao, 2009). U\&G theory posits media use is a way to achieve gratification as well as a means to satisfy psychological needs (Blumler, 1979; Katz, Blumler, \& Gurevitch, 1974; McQuail, Blumler, \& Brown, 1972). As Katz et al. (1974) explained, media users who are active and aware of their own interests tend to use specific 
media to satisfy their needs and as a result achieve higher levels of gratification from that specific source of media.

McQuail (1983) has summarized four types of motivational needs that account for specific use of media: (1) information, which refers to the need of acquiring information and knowledge; (2) personal identity, which refers to the requirement of enhanced personal value and status; (3) social interaction, which refers to the need of maintaining social connection with one's family and friends; and (4) entertainment, which refers to the need of seeking pleasure and enjoyment.

Another characteristic that distinguishes U\&G theory from other theories lies in its particular focus on the users, who have been identified as an active audience (Blumler, 1979; Katz et al., 1974). It is argued that users' activity is an important variable to understand media use, even though not all users can be regarded as active. Specifically, users demonstrate activity within different media through the practices they undertake, and these practices reflect their perceived needs brought about by that specific media (Blumler, 1979; Cheng \& Lo, 2012; Kim \& Rubin, 1997; Rubin, 1993).

When expanded to new media, a growing body of literature has adopted the U\&G paradigm as the primary theoretical framework to understand people's use of various social media (Shao, 2009), such as social network sites (Brandtzæg \& Heim, 2009; Chen, 2011; Park, Kee, \& Valenzuela, 2009), online communities (Wang \& Fesenmaier, 2004), and the new animated media (Cheng \& Lo, 2012). Brandtzæg and Heim (2009) reported that people's use of social network sites is mainly driven by their needs to develop new relations, maintain friends, socialize, gather information, engage in debate, take advantage of free SMS, kill time, share/consume content, profile surf, and maintain family contacts. All motivations fell into the four categories (information, entertainment, social interaction, and personal identity) that are proposed by the U\&G paradigm. Similarly, research examining the new media users found that motivational needs of social interaction, relaxation, information seeking, and entertainment, are taking the leading roles in determining audiences' consumption of animated media content (Cheng \& Lo, 2012).
However, unlike traditional media, social media can be further interpreted as "a collections of feature” (Smock, Ellison, Lampe, \& Wohn, 2011, p. 2323), and therefore the motivational needs of social media users not only decide the selection of the social media platform but also determine the utilization of a specific function within one social media site. Due to this dynamic nature, increasing attention has been focused on the relationship between social media users' motivational needs, activities, and activeness. As one study found, most active members on Twitter are motivated to satisfy their need of social connection (Chen, 2011).

In line with previous research, studies in this area have provided empirical support for the use of U\&G theory within social media; yet, it is noticed that Flickr, as a typical example of image-sharing social media sites, has not been explored using the U\&G paradigm.

\section{Tourists' Use of Social Media}

Tourism is an information-intensive industry, and therefore, the role played by social media in the tourism sector can never be underestimated (Xiang \& Gretzel, 2010). Previous research has depicted tourists' frequent use of social media to share tourism experiences (Lo et al., 2011; Tussyadiah \& Fesenmaier, 2009) as well as search information for travel planning (Xiang \& Gretzel, 2010). In turn, it is reported that the substantial amount of user-generated contents on social media sites can also exert impacts on peoples' tourism decisions (Arsal, Backman, \& Baldwin, 2008; Tussyadiah \& Fesenmaier, 2009; Yoo et al., 2009).

Interestingly, the significant impacts of social media on tourists' decisions are not well documented. However, some research indicates that travel plans may be altered by the use of general social media sites (Milano, Baggio, \& Piattelli, 2011). As suggested by McQuail (1977), users are often affected by the media in an unconscious way. Although some studies have revealed the relationship between consumption of CGM and travel decisions (Fotis, Buhalis, \& Rossides, 2011; Milano et al., 2011), very few studies have been carried out to explore the influence of consuming CGM content on users' travel intentions. 


\section{Research Method}

\section{Research Questions}

The purpose of this study was to understand the phenomenon of food photography in the social media site Flickr (www flickr.com) and to explore the role of food pictures in its members' travel decision process. Specifically, this study attempted to answer the following research questions:

- Do people take pictures of food?

- Where do they photograph the food?

- Do they look at food pictures online? Why?

- Do they post food pictures online?

- What online mediums do they use?

- Do they take pictures of food on vacation? Why?

- Why do people participate in online food photography activities on Flickr?

- What is the role of food pictures in their travel planning process?

\section{Study Site}

Established in 2004, Flickr.com is a public website that is designed for users to upload, store, and share images. It is estimated that there are more than 35 million users on Flickr where more than 3 billion pictures have been shared (Nov et al., 2010). Members of Flickr are able to title, tag, describe, and categorize the pictures. One special function of Flickr is to allow users to form a group under a specific theme; therefore, members of similar interest could share images and have public discussions with each other. As of March 2011, under the key word "food," a total of 26,525 groups could be found on Flickr. Nine of them contain more than 5,000 members. They are "Food Porn" (http://www flickr.com/ groups/food_porn/) (31,449 members), “I Ate This” (http://www.flickr.com/groups/i ate this) (24,246 members), "I love food group" (http://www flickr. com/groups/ilovefood) (23,802 members), “A Food Photography Experience” (http://www flickr.com/ groups/afoodphotograpyexperience) (16,886 members), "Professional looking food photography" (http://www.flickr.com/groups/foodphotography) (13,252 members), "Food from All Over the World" (http://www.flickr.com/groups/foodfromallovertheworld/) (6,739 members), "Food food food"
(http://www.flickr.com/groups/54026309@N00) (6,114 members), “!Flickr food \& Cuisine Around the World”(http://www.flickr.com/groups/cuisines) (6,007 members), and "Delicious Foods” (http://www. flickr.com/groups/deliciousfoods) (5,669 members).

The top nine food groups on Flickr were selected as the study site for this research because they represented the groups with the largest membership base. Flickr was chosen for this study for the following reasons: (1) Flickr is one of the dominant online image-sharing communities that has a large number of members (Nov et al., 2010), and (2) food was found as one of the influential themes on Flickr (Moed et al., 2007). The top nine food groups were featured in this study because of the following reasons. (1) Food groups on Flickr could help researchers gain access to users who are particularly fond of online food photography. (2) All of these selected food groups contain more than 5,000 members, and collectively they can provide a substantial number of subjects that fit our research interest.

\section{Research Design}

A mixed method was adopted for this study. It is believed that a combination of qualitative and quantitative research methods could "answer a broader and more complete range of research questions, provide stronger evidence for a conclusion through convergence and corroboration of findings, as well as increase the generalizability of the results and produce completed knowledge that [is] necessary to inform theory and practice” (Johnson \& Onwuegbuzie, 2004, p. 21).

The research project began with researchers registering as Flickr members and joining all the selected food groups. Researchers then sought out and were given permission by website administrators to contact members of the nine most popular Flickr food groups. With the permission of administrators, short invite notes, which included a brief introduction of the research project, an open-ended question, "Why do you take pictures of food?," and a link to the online survey instrument, were posted on the discussion boards.

Responses to the open-ended questions were collected as qualitative data and then content analyzed using the U\&G paradigm. Such an approach 
allowed researchers to develop a general understanding of members' motivation to participate in a wide variety of food photography activities on Flickr. The quantitative component consisted of respondents completing three sections in the online questionnaire. First, food group members were asked a series of questions that related to online food photography activities, such as whether they take, view, and post food pictures, as well as the main purpose of practicing these activities. Second, on the basis of a 5-point Likert-type scale ranging from 1 (strongly disagree) to 5 (strongly agree), participants were asked to evaluate their level of agreement on different statements describing the role of food pictures in the travel planning process. Lastly, individual characteristics of these participants were examined in terms of their photography ability level, age, gender, education, occupation, and marital status.

\section{Data Analysis}

A total of 102 responses were posted on the discussion boards. A directed content analysis approach was adopted. This approach is appropriate when there is a theory that can guide the analysis (Hsieh \& Shannon, 2005). As suggested by Hsieh and Shannon (2005), the analysis procedure consisted of three steps: (1) identify the main categories based on the guided theory; (2) provide the definition of each category; and (3) highlight the important text and sort them into different categories. According to the U\&G theory (McQuail, 1983), four categories have been identified as follows: (1) entertainment, which refers to the sense of enjoyment, pleasure, and fondness; (2) personal identity, which refers to a type of personal achievement and an enhanced personal status; (3) social interaction, which refers to the social bonding with friends, family, and the surroundings; and (4) information, which refers to the inquiry of information and relevant knowledge.

One hundred sixty-nine members participated in the online survey and were examined descriptively to profile the respondents. Given the importance of users' activities and activeness, respondents who reported taking, viewing, and posting pictures of food online were categorized as "active" members ( $n=129)$, whereas the remaining respondents were categorized as "not-as-active” members $(n=40)$. In order to better understand the features of different users, chi-square tests were employed to determine if significant relationships existed between active members and not-as-active members with respect to individual characteristics. Independent sample $t$ tests were then conducted to determine if significant differences existed between active members and not-as-active members and the role of food pictures in their travel planning process.

\section{Findings and Discussions}

\section{Why Do People Take Pictures of Food?}

Based on the question "why do you take pictures of food?" the U\&G theory guided the content analysis of the open-ended question. Four categories have been proposed, but only three of them have emerged as the main themes: (1) entertainment, (2) personal identity, and (3) social interaction. These themes reveal that online food photography is popular not merely because of people's special interest in food; the activities of consuming CGM was driven by their needs for entertainment, personal identity establishment, and social interaction maintenance. In short, their culinary experiences were recorded personally, but shared socially.

Entertainment. A large portion of respondents expressed their strong affection toward food and photography, just as one respondent said, "I love food, I love photography. Therefore, I love food photography even more.” Another respondent further explained his strong fondness as,

It's beautiful. It's vibrant, food makes me smile, gets you excited, makes everyone happy. The aroma, the warmth, the taste, the sizzle, the crackling of a chicharon. All your senses awaken at the same time. Oh I love to eat. The highlight of my day, the adventure in my life. It's an experience, a journey. ... and sometimes it's just better than sex.

The U\&G theory has depicted that one of the main purposes of members' participation in social media is to look for entertainment, such as relaxing, obtaining aesthetic pleasure, seeking relaxation, and sexual arousal (Shao, 2009). Respondents in 
this study were entertained by both their original interest in food and the aesthetic enjoyment brought by food images. As one participant said, "I take photos of food because I love food, I also love the way food is presented. . . . very artistic," similarly, another participant wrote "as for me, I take food photo because it has lots of color, texture, which give different emotion on it.”

Personal Identity. The importance of personal identity has been addressed by the U\&G theory, because social media sites can provide a platform for users to express themselves and supply users with a tool to construct and display their inherent selfimages (VanLear, Sheehan, Withers, \& Walker, 2005). Likewise, another study also points out that usages of image-sharing social media not only help members record and preserve the memory but also contribute to their personal identity establishment (Van House, 2007). Some of the Flickr members briefly described their utilization of food pictures as "evidence," "daily records," and "a personal, visual record of my memory (and joy) of that meal preserving those memories," whereas others further demonstrated the connection between food photography and their personal image, as they said "where and what you like to eat is part of each individual's personality," "Because I used to be in the art field ... with a strong need to create, (and eat!) . . . my prepared food has now become my palette and canvas.”

Social Interaction. Relationship is another significant characteristic of social media websites (Van House, 2007). The U\&G theory also suggests that maintaining social bonding and social integration is one of the fundamental needs that encourage the extensive use of media (Katz et al., 1974). One Flickr member spoke of his strong intention to share the culinary experience as "food makes me happy and I like sharing the excitement. . ..” Further, it is noticed that these members were well prepared to share their works with a wider audience beyond their acquaintances. Just as one of the respondents said,

... sometime I try to make pictures ... because the effect it has on me and anyone who sees pictures of food. . . . It's like telling a story. If we were in the "caves." Probably not only the best portrait painter would draw his adventures to tell his community about where the food came, but the one who survived ..."

Information. Both the U\&G theory and other studies examining the influences of social media have addressed the importance of social media as information sources (Katz et al., 1974; Xiang \& Gretzel, 2010; Yoo et al., 2009), the current study failed to have the theme related to information provision emerge from the open-ended question. This inconsistency might be caused by the limited size of responses. Another reason might be members' particular interest in food, whereas content is primarily a personal expression of self-relevance where audiences tend to be included in a passive way (Van House, 2007; Yoo et al., 2009).

Apart from that, results from the qualitative analysis were consistent with the U\&G theory and in line with past research (Nov et al., 2010; Van House, 2007; Wang \& Fesenmaier, 2004). Findings of this study have lent credence to the adaptability of U\&G theory within the context of imagesharing social media sites and extended our current knowledge on social media users who have special interests.

\section{Profiling Members in Flickr Food Groups}

Six of 10 (62.2\%) respondents were female and $37.8 \%$ were male. The mean age was 34 years and the median was 31 years. Eight of 10 (81.0\%) of the respondents had a college/university or higher degree. Nearly one half (48.9\%) of the respondents were employed full time and $15.9 \%$ were students. One half (50.8\%) of the respondents had never married, whereas $39.5 \%$ were married, and the rest (13.3\%) were either separated or widowed. When asked to evaluate their photography skill, the majority (83.5\%) regarded themselves as either "intermediate" or "advanced."

Similar to previous studies on social media, the respondents were relatively young and well educated (Ip, Lee, \& Law, 2012; Lo et al., 2011). Different from other studies, a large portion of respondents in this study were female and most participants have never married. This might be explained by the fact that women are more attracted by food (Tse \& 
Crotts, 2005), and the lack of family obligations might provide more free time for singles to participate in culinary activities (Jacobs \& Gerson, 2001).

Food Photography. With respect to the food photography activities, Table 1 indicates that nearly all (92.8\%) respondents took pictures of food, and the main locations where they practiced the activity were home $(87.6 \%)$, restaurants $(65.6 \%)$, and vacation destinations (51.3\%). Nine of 10 (89.9\%) respondents indicated that they also look for food pictures online, and the main reason is to enjoy the pictures of food (83.1\%), learn about different foods $(62.7 \%)$, and learn about different restaurants (32.4\%). One fifth (19.6\%) of the respondents reported other purposes such as to learn new techniques of food photography, to analyze the food photography arts, and to inspire future trips.

Table 1

Activities Related to Online Food Photography

\begin{tabular}{|c|c|c|}
\hline Variable Item & $n$ & $\%$ \\
\hline \multicolumn{3}{|l|}{ Do you take pictures of food? } \\
\hline Yes & 154 & 92.8 \\
\hline No & 15 & 7.2 \\
\hline \multicolumn{3}{|l|}{ Locations where people take pictures of food } \\
\hline Home & 135 & 87.6 \\
\hline Restaurants & 101 & 65.6 \\
\hline Vacation destinations & 79 & 51.3 \\
\hline \multicolumn{3}{|l|}{ Do you look at food pictures online? } \\
\hline Yes & 142 & 89.9 \\
\hline No & 16 & 10.1 \\
\hline \multicolumn{3}{|l|}{ Reasons why you look at food pictures online } \\
\hline To enjoy the pictures of food & 118 & 83.1 \\
\hline To learn about different foods & 89 & 62.7 \\
\hline To learn about different restaurants & 46 & 32.4 \\
\hline \multicolumn{3}{|l|}{ Do you post your food pictures online? } \\
\hline Yes & 144 & 91.1 \\
\hline No & 14 & 8.9 \\
\hline \multicolumn{3}{|l|}{ Preferred medium to upload food pictures } \\
\hline Flickr & 131 & 91.0 \\
\hline $\begin{array}{l}\text { Social network sites (i.e., Facebook, } \\
\text { Twitter) }\end{array}$ & 108 & 75.9 \\
\hline Blogs (i.e., personal blogs, food blogs) & 68 & 47.2 \\
\hline Online photo album (i.e., Picasa) & 20 & 13.9 \\
\hline \multicolumn{3}{|l|}{$\begin{array}{l}\text { Do you take pictures of food while on } \\
\text { vacation? }\end{array}$} \\
\hline Yes & 119 & 80.4 \\
\hline No & 29 & 12.6 \\
\hline \multicolumn{3}{|l|}{$\begin{array}{l}\text { Reasons why you take pictures of food while } \\
\text { on vacation }\end{array}$} \\
\hline To share my experiences with others & 99 & 83.2 \\
\hline To record special events & 72 & 60.5 \\
\hline To help me remember the meal & 70 & 58.8 \\
\hline
\end{tabular}

The majority (91.1\%) of the participants also posted their food pictures online. Their preferred medium to upload food pictures was Flickr (91.0\%), social network sites such as Facebook and Twitter (75.9\%), and personal and food blogs (47.2\%). The results indicated these food group members took pictures of food to share the culinary experiences with others on Flickr as well as other social media sites. This is consistent with previous literature that noticed multiple media platforms were used for posting pictures online (Lo et al., 2011).

Taking Pictures of Food on Vacation. Eight of 10 (80.4\%) respondents indicated that they take pictures of food while on vacation. The main reasons were to share their experiences with others (83.2\%), record special events (60.5\%), and help them remember the meal (58.8\%). There is an inconsistency between the number of respondents who take food pictures at the vacation destination $(n=79)$ and the number who take food pictures while on vacation $(n=99)$. This finding seems to imply that some of the food pictures might be taken during the trip in other locations instead of the destination itself. The difference might suggest that the tourism experience is a multiphase experience (Fridgen, 1984) and that food is a component of travel to and back from the destination. It could also be hypothesized that food photography provides tangible evidence of their intangible tourism experiences rather than a sole record of destinations.

\section{Food and Food Pictures in the Travel Planning Process}

A series of statements was used to assess the role of food and food pictures in the travel planning process using a Likert scale varying from " 1 = Strongly Disagree" to " 5 = Strongly Agree” (see Table 2). It was found that $73.8 \%$ of the respondents agreed or strongly agreed with the statement "I like to first decide the destination for a vacation, and then look for local food and restaurants"; $62.7 \%$ of the respondents agreed or strongly agreed with the statement "I like to go to new places to try some new food and take pictures of them"; $54.1 \%$ of the respondents agreed or strongly agreed with the statement "food pictures motivate me to go to new places"; $46.9 \%$ 
Table 2

The Role of Food and Food Pictures in the Travel Planning Process

\begin{tabular}{lcc}
\hline Item & $M$ & $S D$ \\
\hline $\begin{array}{l}\text { I like to first decide the vacation destination } \\
\text { and then look for local food and } \\
\text { restaurants. }\end{array}$ & 3.74 & 1.17 \\
$\begin{array}{l}\text { I like to go to new places to try some new } \\
\text { food and take pictures of them. }\end{array}$ & 3.53 & 1.27 \\
$\begin{array}{l}\text { Pictures of food motivate me to go to a } \\
\text { new place. }\end{array}$ & 3.43 & 1.12 \\
$\begin{array}{l}\text { If I know of new places through food } \\
\text { pictures, I will go there and try the food. }\end{array}$ & 3.22 & 1.13 \\
$\begin{array}{l}\text { I look at food pictures when planning a } \\
\text { trip (recoded). }\end{array}$ & 3.01 & 1.40 \\
$\begin{array}{l}\text { I like to look up some information on some } \\
\text { new food and then choose a destination }\end{array}$ & 2.37 & 1.16 \\
\begin{tabular}{l} 
where I can find the food. \\
\hline
\end{tabular} & & \\
\hline
\end{tabular}

of the respondents indicated that they would look at food pictures when planning a trip; $46.8 \%$ of the respondents agreed or strongly agreed with the statement "if I know of new places through food pictures, I will go there and try the food"; and $26.2 \%$ of the respondents agreed or strongly agreed with the statement "I like to look up information on some new food and then choose a vacation destination where I can find the food.”

Active Members and Not-as-Active Members. Member's participation has been highlighted as one of the fundamental dimensions to examine users' attitudes and behaviors within online travel communities (Blumler, 1979; Buhalis \& Law, 2008; Vogt \& Fesenmaier, 1998), not only because social media users' activities and activeness are closely connected with each other (Blumler, 1979), but also that member's participation and active contribution are positively related with each other (Wang \& Fesenmaier, 2004), and a positive attitude could actually strengthen members' intention to follow the information they obtained in CGM content (Casaló, Flavián, \& Guinalíu, 2011). Thus, to explore the influence of taking, viewing, and posting food pictures on the travel planning process, group members were divided into two segments. Respondents who take pictures of food, view, and post food pictures online were labeled as "active members” $(n=129)$. The other segment, "not-as-active members" $(n=40)$, included members who did not practice all these activities at the same time. As shown in Table 3, the results of chi-square tests indicate that there was no significant relationship between the two segments and age $\left(x^{2}=0.65\right.$, $p=0.72)$, gender $\left(x^{2}=1.39, p=0.19\right)$, occupation $\left(x^{2}=5.91, p=0.52\right)$, and taking pictures of food while on vacation $\left(x^{2}=0.002, p=0.58\right)$, whereas significant relationships were found between the segments education $\left(X^{2}=20.18, p \leq 0.001\right)$, marital status $\left(X^{2}=20.73, p \leq 0.001\right)$, and photography skill $\left(x^{2}=17.93, p \leq 0.001\right)$.

Consistent with previous studies, the results revealed that individuals with higher education were more likely to use social media as well as travel websites to share their tourism experiences (Ip et al., 2012; Lo et al., 2011). It is interesting to note that significant differences existed between marital status and active members versus not-as-active members. As mentioned, this might be explained by the fact that the singles have more time and energy to devote themselves to leisure activities (Jacobs \& Gerson, 2001). As for the skill differences, the feature of Flickr as a photographic community site might be part of the reason.

Table 4 presents the results of a series of independent $t$-test results that examined the influence of taking, viewing, and posting food pictures on the travel planning process. The food picture segment (active members and not-as-active members) was the independent variable and the six travel decisions statements were the dependent variables. Four out of six statements were found significantly different between the two segments. For active members, they were significantly more likely to go to new places to try some new food and take pictures of them ( $t=2.84, p=0.005)$, motivated to go new places by food pictures $(t=2.72, p=0.007)$, go try the food if they know of new places through food pictures ( $t=3.57, p=0.007)$, and look at food pictures when planning a trip $(t=2.03, p=0.045)$.

The differences suggest that food photography is more influential for active members in terms of novelty and information inquiry. Numerous tourism studies have demonstrated the significance of novelty-seeking as a travel motivation (Bello \& Etzel, 1985; Crotts, 1993; Lee \& Crompton, 1992). Within a culinary tourism context, novelty has been listed as an antecedent accounting for tourists' 
Table 3

Profiling Active Members and Not-as-Active Members in Flickr Food Groups

\begin{tabular}{|c|c|c|c|}
\hline & $\begin{array}{l}\text { Active Members } \\
\quad(n=129)\end{array}$ & $\begin{array}{l}\text { Not-as-Active } \\
\text { Members }(n=40)\end{array}$ & Significance \\
\hline \multicolumn{4}{|l|}{ Age (\%) } \\
\hline$\leq 35$ years & 58.7 & 62.5 & \multirow{3}{*}{$\begin{array}{l}\chi^{2}=0.65 \\
p=0.72\end{array}$} \\
\hline $36-55$ years & 37.5 & 37.5 & \\
\hline$\geq 55$ years & 3.8 & 0.0 & \\
\hline \multicolumn{4}{|l|}{ Gender (\%) } \\
\hline Female & 64.2 & 50.0 & \multirow{2}{*}{$\begin{array}{l}x^{2}=1.39 \\
p=0.19\end{array}$} \\
\hline Male & 35.8 & 50.0 & \\
\hline \multicolumn{4}{|l|}{ Education (\%) } \\
\hline High school or less & 30.2 & 70.0 & \multirow{2}{*}{$\begin{array}{l}x^{2}=20.18 \\
p<0.001^{* *}\end{array}$} \\
\hline College/university or higher degree & 69.8 & 30.0 & \\
\hline \multicolumn{4}{|l|}{ Marital status (\%) } \\
\hline Never married & 40.3 & 27.5 & \multirow{3}{*}{$\begin{array}{l}\chi^{2}=20.73 \\
p<0.001^{* *}\end{array}$} \\
\hline Married & 34.9 & 1.0 & \\
\hline Others & 24.8 & 62.5 & \\
\hline \multicolumn{4}{|l|}{ Occupation (\%) } \\
\hline Employment full time & 33.3 & 15.0 & \multirow{3}{*}{$\begin{array}{l}\chi^{2}=5.91 \\
p=0.52\end{array}$} \\
\hline Student & 12.4 & 10.0 & \\
\hline Others & 54.3 & 75.0 & \\
\hline \multicolumn{4}{|l|}{ Photography skill (\%) } \\
\hline Audience & 0.0 & 18.8 & \multirow{4}{*}{$\begin{array}{l}\chi^{2}=17.93 \\
p=0.001 * *\end{array}$} \\
\hline Beginner & 13.8 & 6.2 & \\
\hline Intermediate/advanced & 85.0 & 75.0 & \\
\hline Professional & 1.1 & 0.0 & \\
\hline Take pictures of food while on vacation (\%) & 80.5 & 80 & $\begin{array}{l}\chi^{2}=0.002 \\
p=0.58\end{array}$ \\
\hline
\end{tabular}

$* * p<0.01$

Table 4

The Roles of Food and Food Picture in Travel Planning Process Between Active Members and Not-as-Active Members

\begin{tabular}{|c|c|c|c|c|c|c|}
\hline \multirow[b]{2}{*}{ Item } & \multicolumn{2}{|c|}{ Active Members } & \multicolumn{2}{|c|}{$\begin{array}{l}\text { Not-as-Active } \\
\text { Members }\end{array}$} & \multirow[b]{2}{*}{$t$} & \multirow[b]{2}{*}{$p$} \\
\hline & $M$ & $S D$ & $M$ & $S D$ & & \\
\hline $\begin{array}{l}\text { I like to first decide the vacation destination } \\
\text { and then look for local food and restaurants. }\end{array}$ & 3.78 & 1.08 & 3.54 & 1.50 & 0.91 & 0.37 \\
\hline $\begin{array}{l}\text { I like to go to new places to try some new } \\
\text { food and take pictures of them. }\end{array}$ & 3.66 & 1.21 & 2.88 & 1.36 & 2.84 & $0.005^{* *}$ \\
\hline $\begin{array}{l}\text { Pictures of food motivate me to go to a } \\
\text { new place. }\end{array}$ & 3.54 & 1.06 & 2.87 & 1.23 & 2.72 & $0.007^{* *}$ \\
\hline $\begin{array}{l}\text { If I know of new places through food pictures, } \\
\text { I will go there and try the food. }\end{array}$ & 3.36 & 1.03 & 2.48 & 1.38 & 3.57 & $0.007^{* *}$ \\
\hline $\begin{array}{l}\text { I look at food pictures when planning a } \\
\text { trip (recoded). }\end{array}$ & 3.12 & 1.37 & 2.48 & 1.47 & 2.03 & $0.045^{*}$ \\
\hline $\begin{array}{l}\text { I like to look up some information on some } \\
\text { new food and then choose a destination } \\
\text { where I can find the food. }\end{array}$ & 2.44 & 1.13 & 2.04 & 1.27 & 1.53 & 0.13 \\
\hline
\end{tabular}

${ }^{*} p<0.05,{ }^{* *} p<0.01$. 
seeking culinary tourism experience (Tse \& Crotts, 2003). Such similarities suggest that food pictures might be able to act as main travel motivators for active members. Moreover, previous research has shown that users' trust of CGM is dependent on the types of website on which the CGM is posted and the perceived credibility of the CGM creators (Yoo et al., 2009). This study found that there is also significant relationship between members' active level and the possibility they would adopt CGM as information sources.

\section{Conclusions}

Combining popular trends of online food photography and culinary tourism, this study not only attempted to document the phenomenon of pop culture but also intended to explore its underlying components. Grounded within the U\&G theory, this study aimed to understand the general motivation of Flickr members' involvement in different online food photography activities as well as the influences of food images in their travel planning process. Results of qualitative and quantitative analyses in this study complemented each other. The descriptive analyses indicated that most Flickr food group members could be described as well educated, fully employed, in their mid-30s, never been married, and labeled as active members, who not only take pictures of food but also post them and look at other food pictures online. Meanwhile the content analysis from the open-ended question revealed only three of the four themes identified by Uses and Gratification. Interestingly, however, in the quantitative survey this theme revealed itself as the second most dominant "reason" for looking at food photos online. This suggests perhaps a gap between why people post and why they look at food pictures. However, due to the small sample number of responses to the open-ended question further research is needed to ensure that this is truly an omission or one due to limitations of this study. Additionally, the findings suggest significant differences between active members and not-as-active members in several individual characteristics, such as education, marital status, and photography skill. Significant relationships could also be found between members' active level and the role of food images in their travel planning process. Food images appeared to be more influential on active members' travel decisions in terms of novelty and providing information.

From a theoretical perspective, the contributions of this study are twofold. First, the results of this study have garnered support for the credibility and applicability of U\&G theory in the new media context of image-sharing social media sites and added greater depth to our current knowledge of social media users. Second, findings from this study have expanded our understanding of the influences of CGM content. It is noted that Flickr members were affected by the media content but in an unconscious way. This influence seemed to be directly related to the attributes of the site. In a sense, travel sites that incorporate food pictures may also play a significant role in users' travel decision. Another interesting finding of this study is that the intensity of the media varies with users' activeness; that is, active members are more likely to be influenced through consuming CGM contents than not-as-active members.

Practically, it is noted that social media in general has changed tourists' behaviors (Lo et al., 2011). In particular, modern tourists are more apt to participate in a wide range of activities on social media sites and use CGM as references for their travel planning. Linked to this study, the growth in culinary tourism represents a promising niche market (US Travel Association, 2007). In this sense, findings of this research not only document how these trends entwine with each other but also provide practical implications for DMOs and tourism marketing professionals to take advantage of them.

Specifically, most members in the active Flickr food group have the potential to be targeted as culinary tourists. As previous literature suggests, people who are involved with food-related activities are more likely to become culinary tourists (Long, 2004; Mitchell \& Hall, 2002). Social media sites with such a specific theme could provide the opportunity for the DMOs to buy advertising space on the sites that promote a culinary experience. Moreover, because more active members tend to be more influenced by novel destinations, this information could be made available to specific destinations that are already marketing to culinary tourists. Provision of the findings would help these destinations put together more targeted, attractive promotions to lure potential markets. 
Furthermore, encouraging audience participation and contribution could be another promotional program for DMOs. For example, rewards could be provided for the "best" food picture taken while on vacation. According to a survey conducted by Nielsen (2006), it was reported that the majority (90\%) of social media users were regarded as lurkers who read the online contents without participation. Thus, encouraging participation through rewards might help to provide a stronger more targeted database for growth in culinary tourism in the destination.

Moreover, the baseline of this study lies in the centrality of food to both culinary tourists and Flickr food group users. In light of this similarity, other special interest groups, such as heritage tourists, adventure tourists, and ecotourists, could adopt a similar strategy; that is, to approach the potential market through subgroups within different social media sites and attract them by enhanced social media and destination promotional programs.

\section{Limitations and Future Research}

Several limitations are associated with this study. First, the qualitative analysis may be limited due to the small number of responses and the adoption of directed content analysis. Therefore in-depth studies are necessary in the future to obtain a comprehensive understanding of members' use of social media sites and the impacts of these sites.

Second, the relatively small sample size in the quantitative portion is also concern. With only 169 members participating in this survey, it is difficult to generalize the heterogeneous nature of the entire food group Flickr members to the entire population. More rigorous survey procedures should be implemented in the future research. Third, this study is delimited to non-Flickr users, whereas multiple social media platforms have been used to upload pictures and there is an increasing number of new social media sites; therefore, future research should focus more on the innovative social media sites, such as Twitpic, Instagram, and Pinterest.

\section{References}

Ab Karim, S., \& Chi, C. G. Q. (2010). Culinary tourism as a destination attraction: An empirical examination of destinations' food image. Journal of Hospitality Marketing \& Management, 19(6), 531-555.
Akehurst, G. (2009). User generated content: The use of blogs for tourism organizations and tourism consumers. Service Business, 3(1), 51-61.

Arsal, I., Backman, S., \& Baldwin, E. (2008). Influence of an online travel community on travel decisions. In P. O’Connor, W. Höpken, \& U. Gretzel (Eds.), Information and communication technologies in tourism 2008 (pp. 82-93). Vienna: Springer.

Bello, D. C., \& Etzel, M. J. (1985). The role of novelty in the pleasure travel experience. Journal of Travel Research, 24(1), 20-26.

Blumler, J. G. (1979). The role of theory in uses and gratifications studies. Communication Research, 6(1), 9-36.

Boniface, P. (2003). Tasting tourism-travelling for food and drink: New directions in tourism analysis. London, UK: Ashgate.

Brandtzæg, P. B., \& Heim, J. (2009). Why people use social networking sites. In P. Zaphiris (Ed.), Communities and social computing (pp. 143-152). Berlin: Springer.

Buhalis, D., \& Law, R. (2008). Progress in information technology and tourism management: 20 years on and 10 years after the Internet-The state of eTourism research. Tourism Management, 29(4), 609-623.

Casaló, L. V., Flavián, C., \& Guinalíu, M. (2011). Understanding the intention to follow the advice obtained in an online travel community. Computers in Human Behavior, 27(2), 622-633,

Chen, G. M. (2011). Tweet this: A uses and gratifications perspective on how active Twitter use gratifies a need to connect with others. Computers in Human Behavior, 27(2), 755-762.

Cheng, B. K. L., \& Lo, W. J. (2012). Can news be imaginative? An experiment testing the perceived credibility of melodramatic animated news, news organizations, media use, and media dependency. Electronic News, 6(3), 131-150.

Crotts, J. C. (1993). Personality correlates of the novelty seeking drive. Journal of Hospitality \& Leisure Marketing, 1(3), 7-29.

Dietler, M. (2007). Culinary encounters: Food, identity, and colonialism. In K. C. Twiss (Ed.), The archaeology of food and identity (pp. 218-242). Carbondale, IL: Southern Illinois University.

Du Rand, G. E., \& Heath, E. (2006). Towards a framework for food tourism as an element of destination marketing. Current Issues in Tourism, 9(3), 206-234.

Everett, S. (2008). Beyond the visual gaze? The pursuit of an embodied experience through food tourism. Tourist Studies, 8(3), 337-358.

Fotis, J., Buhalis, D., \& Rossides, N. (2011). Social media impact on holiday travel planning: The case of the Russian and the FSU markets. International Journal of Online Marketing, 1(4), 1-19.

Fridgen, J. D. (1984). Environmental psychology and tourism. Annals of Tourism Research, 11(1), 19-39.

Frochot, I. (2003). An analysis of regional positioning and its associated food images in French tourism regional brochures. Journal of Travel \& Tourism Marketing, 14(3-4), 77-96. 
Garrod, B. (2008). Exploring place perception a photo-based analysis. Annals of Tourism Research, 35(2), 381-401.

Hall, C. M., \& Mitchell, R. (2000). Wine tourism in the Mediterranean: A tool for restructuring and development. Thunderbird International Business Review, 42(4), 445-465.

Hall, C. M., \& Mitchell, R. (2002). Tourism as a force for gastronomic globalization and localization. In A. M. Hjalager \& G. Richards (Eds.), Tourism and gastronomy (pp. 71-90). London: Routledge.

Hsieh, H. F., \& Shannon, S. E. (2005). Three approaches to qualitative content analysis. Qualitative Health Research, 15(9), 1277-1288.

Ip, C., Lee, H. A., \& Law, R. (2012). Profiling the users of travel websites for planning and online experience sharing. Journal of Hospitality \& Tourism Research, 36(3), 418-426.

Jacobs, J. A., \& Gerson, K. (2001). Overworked individuals or overworked families? Explaining trends in work, leisure, and family time. Work and Occupations, 28(1), 40-63.

Jenkins, O. (2003). Photography and travel brochures: The circle of representation. Tourism Geographies, 5(3), 305-328.

Johnson, R. B., \& Onwuegbuzie, A. J. (2004). Mixed methods research: A research paradigm whose time has come. Educational Researcher, 33(7), 14-26.

Katz, E., Blumler, J. G., \& Gurevitch, M. (1973). Uses and gratifications research. The Public Opinion Quarterly, 37(4), 509-523.

Kim, J., \& Rubin, A. M. (1997). The variable influence of audience activity on media effects. Communication Research, 24(2), 107-135.

Kivela, J., \& Crotts, J. C. (2006). Tourism and gastronomy: Gastronomy's influence on how tourists experience a destination. Journal of Hospitality \& Tourism Research, 30(3), 354-377.

Larsen, J. (2006). Geographies of tourist photography: Choreographies and performances. In J. Falkheimer \& A. Jansson (Eds.), Geographies of communication: The spatial turn in media studies (pp. 243-261). Gøteborg, Sweden: Nordicom.

Lee, T. H., \& Crompton, J. (1992). Measuring novelty seeking in tourism. Annals of Tourism Research, 19(4), 732-751.

Lo, I. S., McKercher, B., Lo, A., Cheung, C., \& Law, R. (2011). Tourism and online photography. Tourism Management, 32(4), 725-731.

Long, L. (2004). Culinary tourism. Lexington, KY: The University Press of Kentucky.

Mack, R., Blose, J., \& MacLaurin, T. (2009). Segmenting the culinary tourist market: An American and Australian comparison. Paper presented at the Proceedings of the 2009 Oxford Business \& Economics Conference Program, June 24-26, 2009, St. Hugh's College, Oxford University, Oxford, UK.

Mak, A. H., Lumbers, M., Eves, A., \& Chang, R. C. (2012). Factors influencing tourist food consumption. International Journal of Hospitality Management, 31(3), 928-936.

Markwell, K. W. (1997). Dimensions of photography in a nature-based tour. Annals of Tourism Research, 24(1), 131-155.
McKercher, B., Okumus, F., \& Okumus, B. (2008). Food tourism as a viable market segment: It's all how you cook the numbers! Journal of Travel \& Tourism Marketing, 25(2), 137-148.

McQuail, D. (1977). The influence and effects of mass media. In J. Curran, M. Gurevitch, J. Woollacott, J. Marriott, \& C. Roberts (Eds.), Mass communication and society (pp. 70-93). Beverley Hills, CA: Sage.

McQuail, D. (1983), Mass communication theory. London: Sage.

McQuail, D., Blumler, J. G., \& Brown, J. R. (1972). The television audience: A revised perspective. In P. Marris \& S. Thornhan (Eds.), Media studies: A reader (pp. 438-454). New York: New York University Press.

Milano, R., Baggio, R., \& Piattelli, R. (2011). The effects of online social media on tourism websites. In R. Law, M. Fuchs, \& F. Ricci (Eds.), Information and communication technologies in tourism 2011 (pp. 471-483). Vienna: Springer.

Moed, A., Rosner, D., Van House, N. (2007). Is food scenery? Generative situations in urban networked photography. Paper presented at CHI 2007 Workshop: Image the city: Exploring the practices and technologies of representing the urban environment in HCL, San Jose, CA, USA.

Murphy, K. (2010). First camera, then fork. The New York Times. Retrieved May 23, 2013, from http://www nytimes. com/2010/04/07/dining/07camera html?pagewanted= all\&_r0

Nielsen, J. (2006). Participation inequality: Encouraging more users to contribute to social media. Retrieved October 1, 2013, from http://www nngroup.com/articles/ participation-inequality.

Nov, O., Naaman, M., \& Ye, C. (2010). Analysis of participation in an online photo-sharing community: A multidimensional perspective. Journal of the American Society for Information Science and Technology, 61(3), 555-566.

Okumus, B., Okumus, F., \& McKercher, B. (2007). Incorporating local and international cuisines in the marketing of tourism destinations: The cases of Hong Kong and Turkey. Tourism Management, 28(1), 253-261.

Park, N., Kee, K. F., \& Valenzuela, S. (2009). Being immersed in social networking environment: Facebook groups, uses and gratifications, and social outcomes. Cyber Psychology \& Behavior, 12(6), 729-733.

Pennington-Gray, L., Stepchenkova, S. \& Schroeder, A. (in press). Using the lens of Flickr to understand meanings about the impact of hurricane Sandy on a tourism destination: The Jersey shore. International Journal of Tourism Anthropology.

Quan, S., \& Wang, N. (2004). Towards a structural model of the tourist experience: An illustration from food experiences in tourism. Tourism Management, 25(3), 297-305.

Rubin, A. M. (1993). Audience activity and media use. Communications Monographs, 60(1), 98-105.

Scarpato, R. (2002). Gastronomy as a tourist product: The perspective of gastronomy studies. In A. M. Hjalager \& G. Richards (Eds.), Tourism and gastronomy (pp. 51-70). London: Routledge. 
Shao, G. (2009). Understanding the appeal of user-generated media: A uses and gratification perspective. Internet Research, 19(1), 7-25.

Sims, R. (2009). Food, place and authenticity: Local food and the sustainable tourism experience. Journal of Sustainable Tourism, 17(3), 321-336.

Smith, S., \& Costello, C. (2009). Culinary tourism: Satisfaction with a culinary event utilizing importanceperformance grid analysis. Journal of Vacation Marketing, 15(2), 99-110.

Smock, A. D., Ellison, N. B., Lampe, C., \& Wohn, D. Y. (2011). Facebook as a toolkit: A uses and gratification approach to unbundling feature use. Computers in Human Behavior, 27(6), 2322-2329.

Tikkanen, I. (2007). Maslow's hierarchy and food tourism in Finland: Five cases. British Food Journal, 109(9), 721-734.

Tse, P., \& Crotts, J. C. (2005). Antecedents of novelty seeking: International visitors' propensity to experiment across Hong Kong's culinary traditions. Tourism Management, 26(6), 965-968.

Tussyadiah, I. P., \& Fesenmaier, D. R. (2009). Mediating tourist experiences: Access to places via shared videos. Annals of Tourism Research, 36(1), 24-40.

Urry, J. (1990). The tourist gaze. London: Sage.

US Travel Association. (2007). Comprehensive culinary travel survey provides insights on food and wine travelers. Retrieved May 23, 2013, from http://www.ustravel. org/news/press-releases/comprehensive-culinary-travelsurvey-provides-insights-food-and-wine-travelers

US Travel Association. (2013). U.S. travel answer sheet 2013. Retrieved May 23, 2013, from http://www.ustravel. org/sites/default/files/page/2009/11/USTravelAnswer Sheet.pdf

Van der Veen, M. (2008). Food as embodied material culture: Diversity and change in plant food consumption. Journal of Roman Archaeology, 2008 (21), 83-109.
Van House, N. (2007). Flickr and public image-sharing: Distant closeness and photo exhibition. In $\mathrm{CHI}$ '07 extended abstracts on human factors in computing systems. New York: ACM Press.

Van House, N. A. (2009). Collocated photo sharing, storytelling, and the performance of self. International Journal of Human-Computer Studies, 67(12), 1073-1086.

VanLear, C. A., Sheehan, M., Withers, L. A., \& Walker, R. A. (2005). AA online: The enactment of supportive computer mediated communication. Western Journal of Communication, 69(1), 5-26.

Vogt, C. A., \& Fesenmaier, D. R. (1998). Expanding the functional information search model. Annals of Tourism Research, 25(3), 551-578.

Wang, Y., \& Fesenmaier, D. R. (2004). Towards understanding members' general participation in and active contribution to an online travel community. TourismManagement, 25(6), 709-722.

Wolf, E. (2002). Culinary tourism: A tasty economic proposition. Portland, OR: International Culinary Tourism Task Force.

World Food Travel Association. (2012). What is food tourism. Retrieved May 23, 2013, from http://www.worldfoodtravel.org/our-story/what-is-food-tourism

Xiang, Z., \& Gretzel, U. (2010). Role of social media in online travel information search. Tourism Management, 31(2), 179-188.

Yoo, K. H., Lee, Y., Gretzel, U., \& Fesenmaier, D. R. (2009). Trust in travel-related consumer generated media. In W. Hopken., U. Gretzel, \& R. Law (Eds,). Information and communication technologies in tourism 2009 (pp. 49-59). Vienna: Springer.

Yun, D., Hennessey, S. M., \& MacDonald, R. (2011). Understanding culinary tourists: Segmentations based on past culinary experiences and attitudes toward food-related behavior. Paper presented at the 2011 International CHRIE Conference, Denver, Colorado. 